\title{
SILENCE IN THE TOWER: ANALYSING THE REASONS OF AIR TRAFFIC CONTROLLERS AVOIDING VOLUNTARY REPORTING
}

\author{
Ilker UNDER (Di) 1,*, Ender GEREDE (D) ${ }^{2}$ \\ ${ }^{1}$ Graduate School of Social Science, Anadolu University, Eskisehir, Turkey \\ ${ }^{2}$ Faculty of Aeronautics and Astronautics, Eskisehir Technical University, Eskisehir, Turkey
}

Received 25 May 2020; accepted 30 October 2020

\begin{abstract}
Defined in the organizational behavior literature as employee avoidance of expressing their feelings, thoughts and ideas, the concept of organizational silence refers to the failure to submit reports voluntarily in the context of aviation safety. Due to various factors, aviation employees may avoid reporting. However, managers need voluntary reports from their employees to prevent future accidents. The primary purpose of this study is to find out why air traffic controllers, one of the most critical safety components of flight operation, fail to do voluntary reporting. In addition, whether controllers are involved in real-life voluntary reporting and whether the factors that prevent voluntary reporting vary by demographic variables. The data collected from 212 controllers were subjected to Confirmatory Factor Analysis by using the Statistical Package for Social Sciences (SPSS) 24 program and the reasons for their failure to do voluntary reporting were identified. Furthermore, the study concluded that approximately $27 \%$ of controllers did not submit voluntary reporting on unsafe situations or safety-enhancing recommendations they had seen.
\end{abstract}

Keywords: aviation, voluntary reporting, safety management system, air traffic control, organizational silence, human factors.

\section{Introduction}

The air transport industry plays a key role in the development of the global economy and the development of countries (International Civil Aviation Organization, 2018). According to the International Air Transport Association [IATA] report, the number of passengers worldwide is expected to increase to 8.2 billion passengers by 2037 , from about 4 billion in 2017 (International Air Transport Association, 2018). This expectation of growth is driven by the benefit of being able to travel farther distances in a much faster and safer way. However, these expected benefits from air transport depend on its safety performance (Gerede, 2015a) since poor safety performance reduces revenues and passenger confidence while increasing costs (Gao et al., 2013). Such low safety performance makes it inevitable that the demand for air transport will fall, resulting in huge socio-economic losses (Ünder, 2016).

Research has shown that employees can remain silent in organizations for various reasons, and the cost may be much higher than previously thought (Perlow \& Williams, 2003). In the case of aviation organizations, silence can adversely affect aviation safety (Bienefeld \& Grote, 2012). If employees in aviation organizations remain silent or their voices cannot be heard, valuable safety data that will help increase aviation safety cannot be obtained (Bienefeld \& Grote, 2012; Morrison \& Milliken, 2000). In this case, since the safety performance will decrease, the expected benefits from air transport will not be acquired and the cost of unsafety will increase. It is beneficial to prevent the silence of air traffic controllers' to increase safety performance.

The rate of fatal accidents in the aviation system, viewed as a socio-technical system that includes the air traffic control (ATC) processes, is actually quite low. Increasing safety only by learning from accidents is not feasible due to the small number of accidents that produce fatal results. Doubtlessly, accidents create learning opportunities, but they come at a great cost, with precious lives lost and great harm done. This method of reactive learning is a product of the traditional safety management approaches. Accident investigations do not yield sufficient quantity and quality of data to find organizational and hidden factors, uncover root causes, and identify future trends. What is more effective is the assessment of safety performance based on unsafe events that do not result in accidents and the safety hazards that cause them (Gerede,

*Corresponding author. E-mail: ilkerundr@gmail.com 
2018). This makes it possible to prevent future accidents, in other words, to be proactive. To achieve all this, obtaining data in a proactive manner rather than reactive one safety is vital (International Civil Aviation Organization, 2013). Indeed, the success of the Safety Management System (SMS), which allows implementing the next-generation safety management approaches to real-life conditions by presenting a performance-based approach, depends on the acquisition of quality safety data (Gerede, 2015b).

In brief, reporting unsafe events and safety hazards that appear to be insignificant but pave the way for accidents, rather than accidents themselves, is of great importance. The data in question are revealed by the testimony of the people who carry out these activities themselves at the very end of the aviation processes. In this case, it becomes important how to obtain adequate quality safety data from the employees in question who are the actual performers of these processes. Employees may prefer to remain silent due to various factors. Controllers witness valuable data both concerning their organizational processes and the flight processes they manage. In other words, their data can be used to improve the safety of both the air traffic management system and flight processes. As such, the success of the reporting and the resulting success of safety management depends on learning the reasons behind controllers' lack of involvement in voluntary reporting. Improvements in the success of voluntary reporting can only be made if the factors hindering such reporting are known.

\section{Conceptual framework}

\subsection{Air traffic control services and aviation safety}

ATC service is defined as managing every stage of flight to prevent aircraft from colliding with each other or hitting other obstacles, in other words, ensuring the safe, orderly, and rapid flow of air traffic both in the air and on the ground (International Civil Aviation Organization, 2016; Uslu \& Dönmez, 2017). ATC service provides three services to aircraft: tower control, approach control, and aerodrome control (International Civil Aviation Organization, 2016).

Air traffic controllers are the employees who provide ATC services to aircraft. They provide the safety and orderly functioning of the air traffic flow by providing various information, instructions and advice via radio to the pilots with whom they communicate on board the aircraft. The information the controllers transmit to the pilots may relate to the route, altitude, speed or airport of destination, as well as to meteorological conditions (International Civil Aviation Organization, 2016; Uslu \& Dönmez, 2017). Therefore, controllers make an important contribution to aviation safety through the information they convey. However, as with other aviation employees, controllers can threaten safety by making errors and violations under the influence of various factors. Indeed, in a report published in 2002, EUROCONTROL noted that excessive workload negatively affects human performance and emphasized that fatigue can negatively affect situational awareness, error management, and human performance (EUROCONTROL, 2002).

Aviation operations cover extremely complex processes with high risks (Gao et al., 2013). Of all commercial flights that took place in 2018, 62 accidents resulted in fatalities (International Civil Aviation Organization, 2018). Despite this, researchers have found that hundreds or even thousands of safety-threatening situations are encountered before an accident occurs and they state that these situations go unreported because they do not produce any serious results (Reason, 1997). However, in a different context, the safety hazards that cause these unsafe events, which do not result in any severe consequences, can also cause an accident. For this reason, even if there are no accidents, there is a great benefit in knowing the factors that cause unsafe events that are low in severity.

Examining the reasons for the occurrence of aircraft accidents in the early stages of aviation reveals that these accidents were caused mostly by significant technical factors. Thanks to the advances in technology, the aircraft accidents that occur today are largely due to human errors and the organizational factors that cause them, rather than technical ones (International Civil Aviation Organization, 2013). When aircraft accidents resulting in fatalities are analyzed, it is noted that approximately $5 \%$ of these accidents are caused by controllers. For example, in the plane crash in which 71 people died as a result of the collision of two planes over Überlingen on July 1, 2002, it was revealed that a controller left his place of duty despite the ban. Later, it was determined that the mistakes made by the other controller, who had to track 3 planes from 2 monitors, caused the accident (German Federal Bureau of Aircraft Accidents Investigation, 2004). Although this rate of 5\% may seem very low considering all accidents occurring, the indirect effect of controllers in pilot-induced accidents should not be ignored (Moon et al., 2011). Problems in the interaction of controllers with pilots, in particular, play an important role in reducing aviation safety (Skybrary, 2019), which make us turn our attention to the air traffic controllers involved in the extreme end of aviation operations, who are tasked with helping aircraft carry out their flight operations safely. Air traffic controllers' reporting of any unsafe situations observed in this process and their suggestions for increasing safety is invaluable in the prevention of possible accidents. However, it is thought that controllers remain silent in the face of unsafe situations for a variety of reasons, by not voluntarily reporting the relevant hazards and incidents (Liao, 2015). Therefore, it is highly critical for aviation organizations and managers to investigate why voluntary reporting is not carried out, which is of great importance in preventing accidents and incidents and improving safety performance.

\subsection{Organizational silence}

Organizational silence is defined as an individual's deliberate retention of information, thoughts, and feelings, which are potentially important for business and organizational 
processes (Dyne et al., 2003; Morrison \& Milliken, 2000). Research suggests that employees have information that can contribute to various problems or situations in the organization (Morrison \& Milliken, 2000) but reveals that they are reluctant to speak out (Bowen \& Blackmon, 2003). Morrison and Milliken (2000) state that this situation negatively affects the development and change of the organization.

One of the most important issues addressed in the organizational silence literature is undoubtedly the determination of why employees remain silent. Pinder and Harlos (2001), among the first to address employee silence, address employee silence in a multidimensional way by stating that employees remain silent based on quiescence and acquiescence. According to Pinder and Harlos (2001), workers who remain silent due to quiescence and acquiescence are aware of the alternatives but remain silent thinking that speaking will not provide any benefits. Employees who act on self-protection think that something bad will happen as a result of their conversations and tend to remain silent proactively. Dyne et al. (2003) state that employees remain silent in a way that is acquiescent, defensive and prosocial. Brinsfield (2013) categorizes employees' silence into the dimensions of six motives: ineffectual, relational, defensive, diffident, disengaged, and deviant. Based on the organizational silence literature, Ünder (2016) gathered the reasons behind maintenance personnel's avoidance of voluntary reporting under four factors: silence based on relational and prosocial, silence based on the disengaged, silence based on quiescence and acquiescence, and silence based on fear and defensive. Therefore, while there is no consensus in the literature on determining the reasons for which employees remain silent, some of the accepted factors related to silence are given above.

Managers in aviation organizations expect their employees not to remain silent in the face of unsafe, risky situations. Aviation employees' speaking out and not remaining silent in their organizations indicates satisfactory and effective voluntary reporting in quantitative and qualitative terms. The most important vocal resource for employees regarding aviation safety is voluntary reporting (Ünder, 2016). In this study, the reasons for employee silence were examined in terms of air traffic controllers, a key element of the aviation system.

\section{Method}

\subsection{Aim of the study}

Ünder (2016) has developed a scale to determine the reasons why aircraft maintenance technicians in Turkey are not involved in voluntary reporting. In this study, the researcher first performed an explanatory factor analysis and, using a four-dimensional structure, revealed why aircraft maintenance technicians avoided voluntary reporting. These non-reporting dimensions are based on relational and prosocial, fear and defensive, quiescence and acquiescence and disengaged. The four-factor structure was then tested with Confirmatory Factor Analysis (CFA) and it was concluded that four latent components explain the voluntary non-reporting variable.

The first objective of the current study is to verify the four-factor structure of Ünder (2016) on the reasons why aircraft maintenance technicians are not involved in voluntary reporting in a different sample context. If the structure is confirmed, the reason behind the new sample of air traffic controllers' silence will be revealed, and another aim of the study will be achieved. For this purpose, CFA was carried out with the data obtained. The CFA is an analysis method used to test whether a previously defined structure is verified (Çokluk et al., 2014).

The second and main objective of the study is to determine whether controllers are involved in real-life voluntary reporting on unsafe situations or safety-enhancing recommendations. Among the additional aims of this study are revealing the relationships between the factors that prevent controllers from making voluntary reporting, determining whether there is a difference between aircraft maintenance technicians and controllers, and finding out whether volunteer reporting averages differ by demographic variables.

\subsection{Universe and sampling}

The universe of the study consists of air traffic controllers in active employment in Turkey. As of 2018, 1475 controllers are working under the General Directorate of State Airports Authority (DHMI) in Turkey (Tunç, 2018). The most important factor underlying this selection of the universe is the critical role of the ATC personnel in ensuring aviation safety. To this end, 212 controllers working in Turkey were reached by using convenience sampling and snowball sampling methods, and the data obtained from 212 participants were analyzed.

\subsection{Data collection tool}

The data collection tool is composed of three sections. The first section employs the data collection tool consisting of 25 items and 4 dimensions developed by Ünder (2016) to find out the reasons for voluntary non-reporting. 5-point Likert scale (1 - Absolutely disagree, 2 - Disagree, 3 - Unsure, 4 - Agree, 5 - Absolutely agree) was used to get the answers of the participants. The second section asks the participants whether they have previously encountered an unsafe incident and safety hazard and reported it. The third section collects the demographic data of the participants.

\subsection{Validity and reliability}

The values for the factor structure of the voluntary nonreporting scale developed by Ünder (2016) are presented in Table 1.

In his study where he developed the scale of voluntary non-reporting (silence), Ünder (2016) reported the Cronbach alpha value to be 0.960 . In the current study, the Cronbach alpha reliability coefficient was found to be 0.930 . 
Table 1. Factor structure of the voluntary non-reporting scale

\begin{tabular}{|l|c|c|c|c|}
\hline \multicolumn{1}{|c|}{ Factor } & Number of items & $\begin{array}{c}\text { Factor load value/ } \\
\text { range }\end{array}$ & $\begin{array}{c}\text { Item total } \\
\text { correlations }\end{array}$ & $\begin{array}{c}\text { Alpha reliability } \\
\text { coefficient }\end{array}$ \\
\hline Relational and Prosocial & 9 & $0.555-0.805$ & $0.584-0.803$ & 0.917 \\
\hline Fear and Defensive & 4 & $0.765-0.880$ & $0.701-0.841$ & 0.899 \\
\hline Quiescence and Acquiescence & 5 & $0.510-0.806$ & $0.596-0.705$ & 0.850 \\
\hline Disengaged & 7 & $0.400-0.782$ & $0.414-0.653$ & 0.792 \\
\hline KMO Value & \multicolumn{4}{|c|}{0.885} \\
\hline Bartlett Sphericity Value & \multicolumn{4}{|c|}{$\mathrm{X}^{2}=3389.375, \mathrm{p}<0.00$} \\
\hline
\end{tabular}

The number of items and Cronbach alpha values as regards the factors are given in Table 1 . These Cronbach alpha values indicate that the scale and the results are reliable (Punch, 2005). Both the item-total correlations and the Cronbach alpha values given in Table 1 show that each dimension has the desired reliability values (Özdamar, 2004). The structure validity of the voluntary non-reporting scale developed by Ünder (2016) was tested by the confirmatory factor analysis for the current study. Kaiser-Mayer-Olkin (KMO) and $(\mathrm{KMO}>0.80)$ Bartlett Sphericity Test $(p<.01)$ show a normal distribution of the data set (Çokluk et al., 2014).

CFA is employed to test the accuracy of a previously established relationship by the researcher (Netemeyer et al., 2003). It provides statistical data on whether the data obtained (observed) by the (proposed) model depicting the relationships between latent variables match (Çokluk et al., 2014).

For this purpose, the four-factor structure proposed by Ünder (2016) was tested with a sample of controllers with first- and second- level CFA. The resulting goodness-offit statistics allow us to comment on how much the data set adapts to previously determined factors (Çokluk et al., 2014; Meydan \& Şeşen, 2001).

In the first-level CFA analysis as shown in Table 2, the Chi-square/DF found to be 2.55. According to the related literature, values below 3 indicate a perfect fit (Kline, 2016). The Root Mean Square Error of Approximation (RMSEA) value is 0.08 , which indicates a good fit. On the other hand, Goodness of Fit Index (GFI) is 0.80 and Comparative Fit Index (CFI) is 0.87 , so both values are moderately compatible. The moderate alignment of the GFI and CFI values can be explained by the small size of the sample (Çokluk et al., 2014).

In the second-level CFA, the model also includes the latent variable for voluntary non-reporting. Based on the fit indices obtained from the second level CFA, four latent variables (relational and prosocial reporting-RPR, fear and defensive reporting-FDR, quiescence and acquiescence reporting-QAR and disengaged reporting-DR)

Table 2. Goodness of fit values based on first level confirmatory factor analysis

\begin{tabular}{|l|c|c|c|c|}
\hline $\begin{array}{l}\text { General } \\
\text { Structure } \\
\text { Fit Indices }\end{array}$ & Chi-square/df & GFI & CFI & RMSEA \\
\cline { 2 - 5 } & 2.550 & 0.800 & 0.870 & 0.080 \\
\hline
\end{tabular}

were combined to explain the voluntary non-reporting (VNR) latent variable. Table 3 shows the fit values. The Chi-square/DF within the second level CFA was found to be 2.55. A Chi-square/SD value below 3 is considered as a perfect fit (Meydan \& Şeşen, 2001). It is observed that RMSEA is 0.08 , GFI is 0.80 , and CFI is 0.87 . The small sample can explain the moderate level of fitness, which is similar to the first-level analysis.

Table 3. Goodness of fit values resulted from second level confirmatory factor analysis

\begin{tabular}{|l|c|c|c|c|}
\hline $\begin{array}{l}\text { General } \\
\text { Structure Fit } \\
\text { Indices }\end{array}$ & Chi-square/df & GFI & CFI & RMSEA \\
\cline { 2 - 5 } & 2.550 & 0.800 & 0.870 & 0.080 \\
\hline
\end{tabular}

Data obtained from the second level CFA shows that the four latent variables (RPR, FDR, QAR, DR) basically explain the voluntary non-reporting variable in ATC. In other words, testing the structure proposed in Ünder (2016)'s earlier work for technicians, the current study concluded that it is valid for the context of air traffic controllers as well. Figure 1 shows the results for the second level CFA.

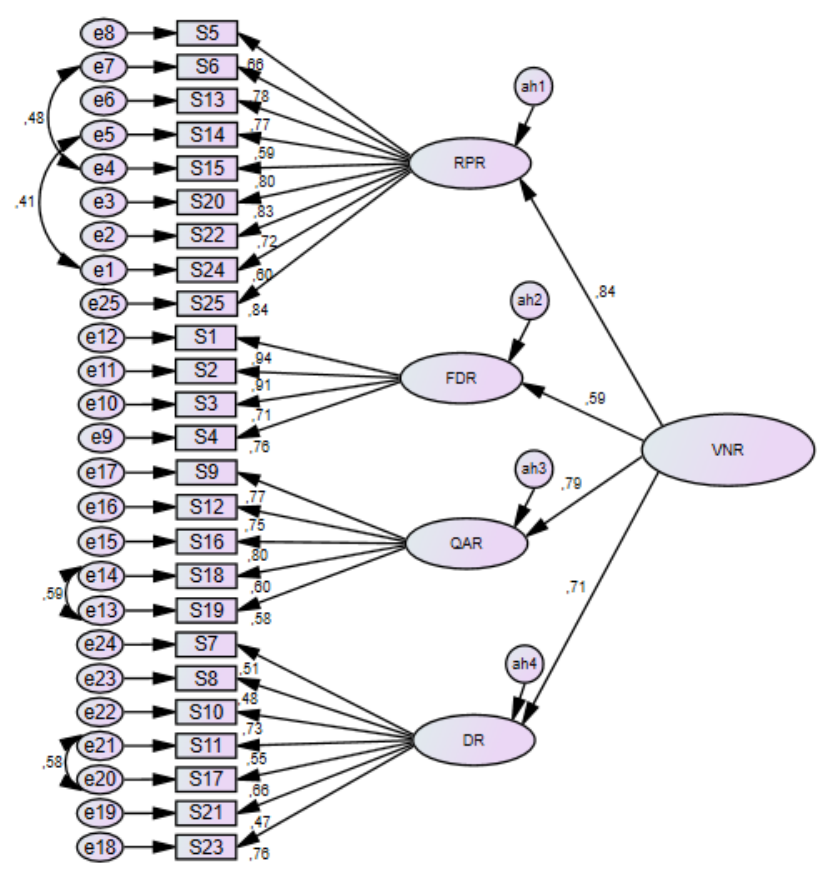

Figure 1. Second level confirmatory factor analysis 


\section{Results}

In the study, a total of 212 participants $35.8 \%$ of whom are female and $64.2 \%$ male. $33.9 \%$ of the participants are 30 or younger. Participants in the 31 and 40 age range account for about $45 \%$ of all the participants. Regarding the education level of the participants, it is noted that approximately $98 \%$ of them have undergraduate or higher degrees. Approximately $70 \%$ of the participants have professional experience of 5 years or more.

To determine whether they submit volunteer reports in real life, the participants were asked the following ques- tion "Have you made any voluntary reporting of any unsafe event, safety hazard or safety-enhancing suggestion?" $17.9 \%$ of respondents stated that they did not experience such a situation requiring reporting, while $26.4 \%$ stated that they had encountered an unsafe situation but did not perform voluntary reporting.

Table 4 shows the four dimensions (reporting based on relational and prosocial, fear and defensive, quiescence and acquiescence, and disengaged) and 25 items of voluntary non-reporting scale statements given to 212 controllers. The table also shows the factor averages for the

Table 4. Voluntary non-reporting scale dimensions and items means



\footnotetext{
${ }^{1}$ European Aviation Safety Agency.

2 Directorate General of Civil Aviation.
} 
four dimensions that constitute voluntary non-reporting, besides the item averages and standard deviations for each of the 25 items that constitute the factors.

The most important reason for silence in controllers is the "non-reporting based on Quiescence and Acquiescence Silence" dimension. The average for this dimension (2.81) was found to be higher than the averages of other 3 -dimensions. There are 5 items under this dimension and the standard deviation values range from 1.216 to 1.314 . These values are considered to be reasonable for interpretation. The most important reason why controllers do not report an unsafe incident or a safety hazard that could potentially threaten safety or fail to propose to improve safety is that they prefer to accept it rather than object to the poor reporting culture, and thus submit to the status quo.

The second most common factor that causes controllers not to engage in voluntary reporting (2.79) is the Voluntary Non-reporting Based on Fear and Defensive Silence. The highest value under this dimension belongs to the statement of "I do not report because I think that I will face the same problems experienced by my co-workers who have previously reported." (3.08). This item ranks second among the items that score the highest points on the 25-item scale. The Voluntary Non-reporting Based on Fear and Defensive Silence is remarkable in this respect.

Another dimension that causes controllers not to engage in voluntary reporting is the Voluntary Non-reporting Based on Relational and Prosocial Silence with an average of 2.44. The fourth dimension that causes controllers not to engage in voluntary reporting is the Voluntary Non-reporting Based on Disengaged Silence, with an average value of 2.2.

The related literature shows a significant relationship between demographic factors and silence. Therefore, we decided to test these relationships in our research. For example, Çakıcı's (2008) study shows that there is a significant difference between men and women's means of silence. Çakıcı explains this situation by stating that possible silence can make employees unhappy. Therefore, first, a t-test was performed, assuming that there could be a difference between male and female controllers in terms of their voluntary non-reporting averages. The result of the t-test was statistically insignificant $(P=0.815)$ (Table 5$)$. Before the analysis, the assumption of homogeneity of the variance of the gender variable was tested (Levene $=0.014, p>0.05$ ) and the homogeneity of its variances was confirmed.

Aliogulları (2012) found that there is a difference between the level of education and organizational silence, and that silence decreases as the level of education increases. He explains this by stating that with the increase of the education level, employees' self-confidence increas-

Table 5. T-test results by gender

\begin{tabular}{|l|c|c|c|c|c|c|}
\hline \multicolumn{1}{|c|}{ Group } & $n$ & Mean & $S D$ & $d f$ & $t$ & $p<$ \\
\hline Male & 136 & 3.486 & 0.708 & \multirow{2}{*}{210} & -0.234 & \multirow{2}{*}{0.815} \\
\cline { 1 - 3 } & 76 & 3.510 & 0.690 & & & \\
\hline
\end{tabular}

es, and therefore they become less silent. On the other hand, there are also studies examining the difference between the experience levels of employees and the average of silence. For example, Bayin et al. (2015) show that silence decreases as professional experience increases. They attributed this to inexperienced employees' not being able to trust their managers due to not knowing them well, and as a result, remaining silent. They also identified statistically significant variations depending on the unit of work.

We further analyzed whether the participants' voluntary non-reporting averages differed significantly according to their experience $(p=0.186)$, work unit $(p=0.421)$ and education levels $(p=0.934)$, and conducted a one-way ANOVA test to find it out. The effect of all three variables on participants' voluntary non-reporting averages was found to be statistically insignificant. The values obtained are given in Table 6. Before the analysis, the homogeneity of the variances was examined. The assumption of homogeneity of the variances of the unit studied (Levene $=$ $0.896, p>.05$ ), level of education (Levene $=0.068, p>.05$ ) and experience (Levene $=1.620, p>.05$ ) was confirmed.

To sum up, the demographic variables do not affect the voluntary non-reporting behaviour of controllers to a statistically significant degree.

The controllers participating in the study were asked whether they were actually doing volunteer reporting, and it was concluded that approximately $27 \%$ of them neither performed volunteer reporting of incidents, safety hazards they had observed nor made any safety-enhancing recommendations on perceived risks. Considering that a safety hazard can be eliminated thanks to information obtained by voluntary reporting, failure to report an unsafe situation means that a future accident cannot be prevented, and a catastrophe may occur (Bienefeld \& Grote, 2012).

Also, a one-way ANOVA analysis was performed to reveal any statistically significant differences between the average scores of the ATC group that has experienced and voluntarily reported a safety hazard, incident or made a proposal to increase the safety, the ATC group that has not performed such reporting, and the ATC group that

Table 6. ANOVA results by experience, work unit and education level

\begin{tabular}{|c|c|c|c|c|c|c|}
\hline Group & $n$ & Mean & $S D$ & $d f$ & $F$ & $p<$ \\
\hline $0.1-5$ years & 70 & 3.500 & 0.747 & \multirow[t]{4}{*}{208} & \multirow[t]{4}{*}{1.620} & \multirow[t]{4}{*}{0.186} \\
\hline $6-10$ years & 67 & 3.395 & 0.595 & & & \\
\hline $11-20$ years & 53 & 3.498 & 0.721 & & & \\
\hline $21+$ years & 22 & 3.772 & 0.761 & & & \\
\hline Tower Control & 98 & 3.555 & 0.699 & \multirow[t]{3}{*}{209} & \multirow[t]{3}{*}{0.869} & \multirow[t]{3}{*}{0.421} \\
\hline Approach Control & 64 & 3.464 & 0.656 & & & \\
\hline Aerodrome Control & 50 & 3.407 & 0.757 & & & \\
\hline Associate & 4 & 3.510 & 0.806 & \multirow[t]{3}{*}{209} & \multirow[t]{3}{*}{2.393} & \multirow[t]{3}{*}{0.094} \\
\hline Undergraduate & 168 & 3.443 & 0.689 & & & \\
\hline Postgraduate & 40 & 3.711 & 0.713 & & & \\
\hline
\end{tabular}


has not faced any such situation (ie. comparison of the reporting, non-reporting, and inexperienced groups)

According to the values presented in Table 7, there is a statistically significant difference between the averages of the ATC groups who performed voluntary reporting when faced with a safety hazard, those who did not, and those with no history of any voluntary reporting situations $(\mathrm{F}(2.209)=14.445 ;<.001)$. Before the analysis, the homogeneity of the variances was examined. According to the reporting history (Levene $=0.742, p>0.05$ ), the assumption of homogeneity of the variances of the variables studied was confirmed.

Table 7. ANOVA results by reporting history

\begin{tabular}{|l|c|c|c|c|c|c|}
\hline \multicolumn{1}{|c|}{ Group } & $n$ & Mean & $S D$ & $d f$ & $F$ & $p<$ \\
\hline Reporting & 118 & 2.337 & 0.689 & 209 & 14.445 & 0.000 \\
\hline Not Reporting & 56 & 2.908 & 0.616 & & & \\
\hline $\begin{array}{l}\text { Not Encountering } \\
\text { any unsafe } \\
\text { incidence or } \\
\text { safety-increasing } \\
\text { recommendation }\end{array}$ & 38 & 2.436 & 0.625 & & & \\
\hline
\end{tabular}

The post-hoc test results revealed a statistical difference between the controllers performing voluntary reporting on a safety hazard, incident or making safety enhancing recommendation $(2.337 \pm, 0.689)$ and those who did not do so $(2.908 \pm 0.616)$.

Correlation analysis is applied to determine whether there is a relationship between two variables (Akbulut, 2010). As such, the correlation analysis was applied to determine whether there was any association between the four factors thought to constitute the reasons for voluntary reporting.

According to the correlation analyses in Table 8, there are positive correlations between non-reporting variables based on relational and prosocial, fear and defensive, quiescence and acquiescence, and disengaged. There is a strong statistically significant and positive correlation between quiescence and acquiescence reporting and relational and prosocial reporting $(r=0.518 ; p<0.01)$. Furthermore, strong statistically significant and positive relationships between the disengaged-based reporting and relational and prosocial-based reporting $(r=0.583$; $p<0.01)$ variables, and disengaged-based reporting and quiescence and acquiescence-based reporting $(r=0.523$; $p<0.01)$ variables.

\section{Discussion}

The question that is worthwhile to answer for improving aviation safety is why air traffic controllers tend to accept and bow to a poor reporting culture. The answer to this question lies in the points given to items below the four dimensions.

According to the results of our study, the Non-Reporting Based on Quiescence and Acquiescence Silence is the primary one among the factors that lead to controllers' exhibiting silent behavior and a lack of voluntary reporting. The item with the highest average value (3.13) in this dimension was "I do not report because I think that the previous reports have been covered up". Under this dimension, the second and third most frequently made statements, respectively, "I do not report because I think our supervisors urging us to report is only lip service." (2.91), and "I do not report because there has been no feedback on the previous reports" (2.85), emerged as the most common causes of silence. When these three highest-ranking reasons for employees not reporting are examined, it can be said that three different perceptions affect the non-reporting behavior: that the reporting is dysfunctional, that they do not create a change towards improving safety, and that the reporting is not considered worthwhile. Failure to report and undervaluing it can cause employees to despair that they cannot change the situation. However, the main purpose of encouraging reporting is to take into account the unsafe incident, hazard or risk mitigating proposal that is subject to the report and to make a change that will improve safety in real-life conditions (International Civil Aviation Organization, 2013). If controllers do not see any change after their reporting of the incident, their belief in the value of reporting may be shaken and they may perceive this behavior as an unnecessary act. The literature (GAIN, 2004; Gerede, 2015a) recommends that to strengthen the positive reporting culture, even reports that do not increase safety should be responded with feedback. In this way, employees will be more likely to think that their behavior of reporting, and not just the content of their report is appreciated. Research in different sectors supports the conclusion that since employees do not receive any feedback to their reports (Özgan \& Külekçi, 2012), they feel that their opinions are not valued, and therefore they exhibit acquiescence behavior (Wood, 2003). The average value of the Non-reporting Based on Quiescence and Acquiescence Silence dimension is observed to be less than 3. Despite the three factors

Table 8. Correlation analysis results

\begin{tabular}{|l|c|c|c|}
\hline \multicolumn{1}{|c|}{$n=212$} & Fear and Defensive & Relational and prosocial & Quiescence and Acquiescence \\
\hline Relational and Prosocial & $0.467^{* *}$ & - & - \\
\hline Quiescence and Acquiescence & $0.462^{* *}$ & $0.518^{* *}$ & - \\
\hline Disengaged & $0.382^{* *}$ & $0.583^{* *}$ & $0.523^{* *}$ \\
\hline
\end{tabular}

Note: ${ }^{* *}$. Correlation significant at 0.01 level (2 way). 
mentioned in this context, the behavior of not reporting due to quiescence and acquiescence by controllers can be said to be low. However, it is noteworthy that this value is close to 3 and the item with the highest average value within the 25 factors falls under this dimension.

If non-reporting behavior based on Quiescence and Acquiescence Silence, the biggest obstacle facing controllers, is to be prevented, then the reports must be definitely processed and evaluated. The rhetoric to encourage reporting, if remained only as a lip service, can undermine employee confidence in the SMS, middle and senior management, and ultimately reduce reporting success. Even if the report content is deemed not worth reporting, or even if the risk mitigation measure in the report is deemed not to work, the reporting employee should be given feedback. It is useful to give feedback on the report to show that employees' thoughts and suggestions are valued (O'Leary \& Chappell, 1996). Sharing an increase in safety or a measure to improve safety across the organization thanks to feedback from employees can also reduce non-reporting behavior based on quiescence and acquiescence.

The second most important factor that causes controllers not to report (2.79) is the Voluntary Non-reporting Based on Fear and Defensive Silence. Employees remain silence because of fear of encountering negative consequences, such as punishment or even dismissal from the workplace (Morrison \& Milliken, 2000). Dyne et al. (2003) argue that such silent behavior results from a wish on the part of employees to protect themselves from any possible harm.

The reason that prevents employees from reporting, regarding this dimension, is the poor positive just culture. In order to overcome these fears of employees, it is essential to strengthen organizational trust and a positive just culture. According to Reason, strengthening a positive just culture depends on the development of trust-based relationships in organizations. Low organizational trust can undermine perceived fairness concerning safety. As a result, it is difficult for employees who experience a crisis of trust and justice to report unsafe events. That's because employees fear being sanctioned, fired or losing their licenses when they report unsafe incidents. Employees expect themselves and the people they report to be protected so that they can report fearlessly (Reason, 1997). Those providing feedback may point out certain incidents, errors and violations which are related to themselves, their friends, their supervisors, the organization itself or other aviation organizations in their reports. All of these can make the reporting person a target. In this case, the persons expected to file a report take into account the past practices and policies of the supervisors. If a following crisis of confidence is envisaged by the employees, their rate of reporting will be reduced. How organizations treat errors and violations as unsafe acts is the most common determinant of just culture. It is recommended to guarantee anonymity in reporting so that silence based on both prosocial tendency and fear and defensive silence can be reduced. In addition, senior management should commit to the safety policy that anonymity is ensured and dem- onstrate that it adheres to this policy through real life behavior (International Civil Aviation Organization, 2013; O'Leary \& Chappell, 1996). Reason (1998) attributes effective reporting to the way an organization handles errors, violations, investigations and sanctions. Dekker and Breakey (2016) stress that disciplinary systems that impose random punishment make employees less likely to report fearlessly.

To describe the employee silence under the influence of fear as selfishness would be, in our opinion, too convenient of an explanation. Not to report based on fear and defensive silence can also be seen as a rational behavior resulting from people's motivation to protect themselves. When employees act on a natural motive and encounter a just culture problem, the success of reporting can be expected to decrease. However, employees are not only expected to report errors or violations made by themselves or by their friends, but also to report ongoing safety hazards (International Civil Aviation Organization, 2013). Organizations with a weak positive just culture may miss the opportunity to learn about incidents and safety hazards.

The second most rated item under this dimension is the statement "I do not report because I do not think there is any legislation in place to protect me in case of an accident investigation." (2.97). Obviously, fatal accidents throughout the world involve forensic investigation and punishment. However, our findings suggest that forensic investigations into unsafe incidents have created a fear of reporting in aviation employees. It is the unique characteristics of socio-technical systems that give rise to the need for a strong positive safety culture. This need arises from the need to know the past, present and future in order to manage both the present and future safety and control. To know, one must first have data, then produce information from the data, and eventually learn. A strong positive reporting culture is needed to collect data, and a learning culture is needed to generate information from data and change organizational behavior. The success positive reporting and learning cultures depends on a strong positive just culture (Gerede, 2018; Reason, 1997, 1998, 2008). Recognizing the importance of positive safety culture, proactivity, and performance-based safety management approaches, the international aviation community is making an intensive effort to bring criminal law solutions that facilitate reporting. Thus, the European Union has ensured that voluntary reports in aviation organizations remain confidential in the prosecution's investigation into aviation accidents.

The fact that the average value (2.79) of the dimension called Voluntary Non-reporting based on Fear and Defensive Silence as the second most common factor that causes controllers not to perform voluntary reporting is less than 3 can be interpreted as positive. It should be noted that this is the second most frequent item (3.08) among all the items.

Another finding in this study is that silence based on prosocial tendency may also hinder reporting. This is because employees are afraid of becoming a whistleblower and being branded as snitches within the group they are 
a member of. Milliken et al. (2003) state that employees can remain silent for fear that their relationship with their friends will deteriorate and they will become stigmatized. In this kind of silence behavior, rather than being afraid of suffering personal harm, the employee is concerned that his/her colleagues may face negative outcomes if $s /$ he speaks. The statement "I do not report because I do not want to stir up trouble with my co-worker(s) by reporting them" which has an average value as high as 2.89 , supports this claim. The statement "I do not report because I do not want to reveal my co-workers' faults and cause them to be punished" with an average of 2.87 , indicates that employees refrain from reporting because they think it will hurt their friends. Indeed, according to Dyne et al. (2003), employees do not remain silent only to avoid harm to themselves. In some cases, they may also avoid reporting certain information to protect their colleagues or organizations. This reason may underlie the high average of controllers' statement that they do not report so as to avoid any harm to their friends.

Reducing the personal and social cost that employees perceive in this context can eliminate such barriers to reporting. It may be emphasized during the controllers' human factors training that notifications should be made to improve safety, not simply to complain to someone or to the organization (International Civil Aviation Organization, 2013). It is also recommended to ensure that the persons reported to have caused safety risks will not be punished for acts other than reckless conduct or sabotage (such as error and negligent conduct). This will strengthen controllers' belief that reporting will not put their friends in a difficult position and that they will not be punished, rejected or embarrassed by their friends. In addition, considering that trust issues can prevent reporting, such an assurance will allow establishing a strong positive just culture and developing mutual trust (Reason, 1997, 1998).

The final reason why controllers are not involved in voluntary reporting concerns disengaged silence. In reference to disengaged silence, Premeaux (2001) asserts that employees exhibit manipulative behaviour and therefore perform benefit-cost analysis before engaging in voluntary reporting. When the relevant statements are examined, the statement "I do not report because I do not think it will benefit me" stands out with an average of 2.9, which supports Premeux (2001). Nevertheless, the average value of 2.2 indicates that disengaged silence is a weak motive for controllers for not reporting. Thus, we recommend that recruitment priority should be given to the personnel who are committed to safety. Staff with a high level of safety dedication would be more likely to report without conducting a cost-benefit analysis in their own interest (Gerede, 2015b). In addition, there is a benefit in increasing the perceived personal benefit of reporting, while reducing the perceived cost (O'Leary \& Chappell, 1996). For example, it may be suggested that the reporters be socially rewarded. Another suggestion may be that those who do not report, although they are supposed to do so, should be socially sanctioned. Peer pressure and conformity can be an effective mechanism in the implementation of social rewards and sanctions (UK Civil Aviation Authority, 2002). Furthermore, it may be suggested that the reporting system should be designed in a straightforward, simple, and time-effective structure to prevent reduced reporting due to disengaged (O’Leary \& Chappell, 1996). The importance of reporting can be emphasized and how to do it and how the system works can be explained in the SMS and Human Factors trainings as well.

There is a statistically significant difference between the averages of the ATC groups who performed voluntary reporting, those who did not, and those with no history of any voluntary reporting situations. The post-hoc test results revealed a statistical difference between the controllers performing voluntary reporting on an incident or making safety enhancing recommendation $(2.337 \pm 0.689)$ and those who did not do so $(2.908 \pm 0.616)$. The fact that the voluntary non-reporting averages of the controllers with the same vocational training and performing the same profession differ statistically underscores the lived experiences of the controllers. When the answers of the controllers who stated that they had not been in voluntary reporting before are examined, the highest average belongs to the statement "I do not report because I think that I will face the same problems experienced by my co-workers who have previously reported." This item has the highest average $(3.48 \pm 1.062)$ on the voluntary nonreporting scale. In other words, the reason behind controllers' not performing voluntary reporting is that they have witnessed the problems that their friends have experienced in the past. Among the answers of the controllers who confirmed engaging in voluntary reporting, the lowest average belongs to the following statement: "I do not report because I do not think reporting is my job." (1.70 \pm 0.720 ). Another low-average statement is "I do not report because I am concerned about being cast out by my coworkers" (1.90 \pm 1.049$)$.

The correlation analysis suggests that situations that push workers into quiescence and acquiescence behaviors also lead them to relational and prosocial behaviors. In other words, the controller who agrees with the statement "I do not report because I do not think that our supervisors like to hear anything negative" may also agree with the statement "I do not report because I do not want to damage my relationships with my supervisor(s) by reporting them" and, thus may be avoiding voluntary reporting not to harm his/her relationship with his/her superiors. Similarly, it can be stated that situations that result in employees not engaging in voluntary reporting due to disengaged silence may lead them to relational and prosocial behavior and cause them not to engage in voluntary reporting. For example, it can be said that the controller agreeing with the statement "I do not report because I do not think reporting will do me any good" which is a statement related to the disengaged silence dimension, will also agree with the statement "I do not report because I do not 
want to be stigmatized as the 'complainer' in my company/ among my co-workers" which is a relational and prosocial statement. In brief, both statements are based on a comparison between the benefit and the harm that employees make before any reporting behavior. As such, the quality and quantity of reporting can be expected to increase if the benefits of reporting and the costs of avoiding reporting for the employee are increased.

While we aim to explore the reasons why air traffic controllers avoid voluntary reporting, there are several limitations to this study. First, we assumed that controllers are adequately aware of voluntary reporting in the study. In another words, they know the importance of voluntary reporting on aviation safety. Second, our survey respondents were chosen from air traffic controllers working in Turkey. Since nation culture, organizational culture, and safety culture that arises out of the both are factors that are likely to affect non-reporting behavior, the analysis and discussion based on the perceptions of the sample respondents may vary if the data was collected from a different region or different sample.

\section{Conclusions and suggestions}

The failure of employees in aviation organizations to report voluntarily on an unsafe event or a safety-enhancing proposal is a major obstacle to preventing a future accident. This is because the lack of voluntary reporting by employees in aviation organizations makes it difficult to access the data needed to manage safety.

Because of this importance, the four-factor structure proposed by Ünder (2016) regarding the reasons why aircraft maintenance technicians did not do voluntary reporting was tested by the confirmatory factor analysis for the case of air traffic controllers. The four-factor structure of the failure of air traffic controllers to report based on relational and prosocial, fear and defensive, quiescence and acquiescence, and disengaged silence was found to be structurally valid.

When asked whether they were doing volunteer reporting, $27 \%$ of controllers gave a negative response. Further, the tests conducted to see whether the voluntary reporting averages of controllers differed in terms of demographic variables found no statistically significant differences. In contrast to the demographic variables, voluntary reporting averages were statistically different in terms of reporting histories $(\mathrm{F}(2.209)=14.445 ;<.001)$.

The correlations between the voluntary reporting dimensions were also investigated via correlation analysis to see whether there was a statistically significant relationship between the dimensions of the voluntary reporting, and the supposed positive relationships among the dimensions of non-reporting were again identified with the help of correlation analysis. The positive strong relationships obtained by the correlation analysis show that each dimension causing controllers not to engage in voluntary reporting is linked to each other by strong relationships.
In brief, given the critical role of controllers in ensuring aviation safety, stronger efforts should be made to understand the reasons why members of this professional group are not engaged in voluntary reporting, without underestimating its significance. It would be helpful to get down to the roots of the impediments preventing voluntary reporting and to break the silence to increase safety. Without reporting, the performance-based safety management approach cannot succeed. Reporting is also the basis of proactivity.

To increase voluntary reporting, we recommend the employees' protection to be fully assured. To this end, senior management should commit to the safety policy of establishing a system in which employees are protected and their voluntary reporting can be done anonymously.

Also, although it is useful to examine the factors of countries such as law, education system and culture, it is beneficial to consider these factors in future studies to focus on the factors of not reporting voluntarily.

\section{References}

Akbulut, Y. (2010). Sosyal bilimlerde spss uygulamaları. İdeal Kültür Yayıncılık.

Alioğulları, Z. D. (2012). Örgütsel sessizlik ve örgütsel vatandaşlı davranışı arasındaki ilişki: Bir uygulama. Atatürk Üniversitesi Sosyal Bilimler Enstitüsü.

Bayın, G., Yeşilaydın, G., \& Esatoğlu, A. E. (2015). Hemşirelerde örgütsel sessizlik nedenlerinin belirlenmesi. Issletme Araştırmaları Dergisi, 7(1), 248-266.

Bienefeld, N., \& Grote, G. (2012). Silence that may kill: When aircrew members don't speak up and why. Aviation Psychology and Applied Human Factors, 2(1), 1-10.

https://doi.org/10.1027/2192-0923/a000021

Bowen, F., \& Blackmon, K. (2003). Spirals of silence: The dynamic effects of diversity on organizational voice. Journal of Management Studies, 40(6), 1393-1417.

https://doi.org/10.1111/1467-6486.00385

Brinsfield, C. T. (2013). Employee silence motives: Investigation of dimensionality and development of measures. Journal of Organizational Behavior, 34(5), 671-697. https://doi.org/10.1002/job.1829

Çakıcı, A. (2008). Örgütlerde sessiz kalınan konular, sessizliğin nedenleri ve algılanan sonuçları üzerine bir araştırma. Ç.Ü. Sosyal Bilimler Enstitüsü Dergisi, 17(1), 117-134.

Çokluk, Ö., Şekercioğlu, G., \& Büyüköztürk, Ş. (2014). Sosyal bilimler için çok değişkenli istatistik: SPSS ve LISREL uygulamaları. Pegem Akademi.

Dekker, S. W., \& Breakey, H. (2016). “Just Culture:” Improving safety by achieving substantive, procedural and restorative justice. Safety Science, 85, 187-193. https://doi.org/10.1016/j.ssci.2016.01.018

Dyne, L. V., Ang, S., \& Botero, I. C. (2003). Conceptualizing employee silence and employee voice as multidimensional constructs. Journal of Management Studies, 40(6), 1359-1392. https://doi.org/10.1111/1467-6486.00384

EUROCONTROL. (2002). Eurocontrol CARE/ASAS Activity 2: Human Performance. Eurocontrol.

GAIN. (2004). A roadmap to a just culture: Enhancing the safety environment. Airbus. 
Gao, Y., Bruce, P. J., Newman, D. G., \& Zhang, C. B. (2013). Safety climate of commercial pilots: The effect of pilot ranks and employment experiences. Journal of Air Transport Management, 30, 17-24. https://doi.org/10.1016/j.jairtraman.2013.04.001

Gerede, E. (2015a). A qualitative study on the exploration of challenges to the implementation of the safety management system in aircraft maintenance organizations in Turkey. Journal of Air Transport Management, 47, 230-240.

https://doi.org/10.1016/j.jairtraman.2015.06.006

Gerede, E. (2015b). A study of challenges to the success of the safety management system in aircraft maintenance organizations in Turkey. Safety Science, 73, 106-116. https://doi.org/10.1016/j.ssci.2014.11.013

Gerede, E. (2018). Havacılikta emniyet yönetimi: Teoriden uygulamaya geleneksel ve yeni nesil yaklaşımlar (1st ed.). Pegem Akademi. https://doi.org/10.14527/9786052412244

German Federal Bureau of Aircraft Accidents Investigation. (2004). Investigation Report, AX001-1-2/02. BFU.

International Air Transport Association. (2018). IATA forecast predicts 8.2 billion air travelers in 2037. https://www.iata.org/ en/pressroom/pr/2018-10-24-02/

International Civil Aviation Organization. (2013). Safety management manual, 9859 AN/474 (3rd ed.). ICAO.

International Civil Aviation Organization. (2016). Air traffic services, Annex 11 (4th ed.). ICAO.

International Civil Aviation Organization. (2018). Safety report. ICAO.

Kline, R. B. (2016). Principles and practice of structural equation modeling (4th ed.). The Guilford Press.

Liao, M.-Y. (2015). Safety culture in commercial aviation: Differences in perspective between Chinese and Western pilots. Safety Science, 79, 193-205.

https://doi.org/10.1016/j.ssci.2015.05.011

Meydan, C. H., \& Şeşen, H. (2001). Yapısal eşitlik modellemesi AMOS Uygulamaları (1st ed.). Detay.

Milliken, F. J., Morrison, E. W., \& Hewlin, P. F. (2003). An exploratory study of employee silence: issues that employees don't communicate upward and why. Journal of Management Studies, 40(6), 1453-1476.

https://doi.org/10.1111/1467-6486.00387

Moon, W.-C., Yoo, K.-E., \& Choi, Y.-C. (2011). Air traffic volume and air traffic control human errors. Journal of Transportation Technologies, 1(3), 47-53.

https://doi.org/10.4236/jtts.2011.13007

Morrison, E. W., \& Milliken, F. J. (2000). Organizational silence: A barrier to change and development in a pluralistic world. Academy of Management Review, 25(4), 706-725. https://doi.org/10.5465/amr.2000.3707697
Netemeyer, R. G., Bearden, W. O., \& Sharma, S. (2003). Scaling procedures: issue and applications. Sage Publications. https://doi.org/10.4135/9781412985772

O’Leary, M. J., \& Chappell, S. L. (1996). Confidential incident reporting systems create vital awareness of safety problems. Journal of the International Civil Aviation Organization, 57(1), $1-6$.

Özdamar, K. (2004). Paket Programlar İle İstatistiksel Veri Analizi (5th ed.). Kaan Kitabevi.

Özgan, H., \& Külekçi, E. (2012). Öğretim elemanlarının sessizlik nedenleri ve üniversitelerine etkileri. E-İnternational Journal of Educational Research, 4(3), 33-49.

Perlow, L., \& Williams, S. (2003). Is silence killing your company? Harvard Business Review, 52-59.

Pinder, C. C., \& Harlos, K. P. (2001). Employee silence: Quiescence and acquiescence as responses to perceived injustice. Research in Personnel and Human Resources Management, 20, 331-369. https://doi.org/10.1016/S0742-7301(01)20007-3

Premeaux, S. F. (2001). Breaking the silence: Toward an understanding of speaking up in the workplace. Louisiana State University.

Punch, K. F. (2005). Sosyal Araştırmalara Giriş: Nicel ve Nitel Yaklaşımlar. D. Bayrak, H. B. Arslan, Z. D. Akyüz, H. B. Arslan, \& Z. Akyüz (Eds.). Siyasal Kitabevi.

Reason, J. T. (1997). Managing the risks of organizational accidents. Ashgate.

Reason, J. T. (1998). Achieving a safe culture: Theory and practice. Work and Stress, 12(3), 293-306. https://doi.org/10.1080/02678379808256868

Reason, J. T. (2008). The human contribution: Unsafe acts, accident and heroic recoveries. Ashgate.

Skybrary. (2019). Pilot-Controller Communications (OGHFA $B N)$. https://www.skybrary.aero/index.php/Pilot-Controller_ Communications_(OGHFA_BN)

Tunç, İ. (2018). Emniyet yönetim sistemi uygulamalarının hava trafik kontrol hizmetlerine katkılarının analizi. Anadolu Üniversitesi.

UK Civil Aviation Authority. (2002). An introduction to aircraft maintenance engineering human factors for JAR 66. The Stationery Office.

Uslu, S., \& Dönmez, K. (2017). Hava trafik kontrol kaynaklı uçak kazalarının incelenmesi. Mehmet Akif Ersoy Üniversitesi Sosyal Bilimler Enstitüsü Dergisi, 9, 271-287.

Ünder, İ. (2016). Havacılıkta örgütsel sessizlik: Havaaracı bakım personelinin raporlamada bulunmamalarının nedenleri üzerine bir araştırma. Anadolu Üniversitesi Sosyal Bilimler Enstitüsü.

Wood, R. H. (2003). Aviation safety programs, a management handbook (3rd ed.). Jeppesen. 